\title{
A cidade começa no lugar onde você mora! Relações entre memória, identidade e território nos bairros-sede dos CEUs ${ }^{1}$
}

The city starts where you live!

Relations between memory, identity and territory in the headquarters neighborhoods of CEUs

\section{Elaine Aparecida Jardim*}

*Arquiteta e urbanista com pós-graduação em análise do discurso de imagens e mestrado em Museologia pela Universidade de São Paulo (2017). Atua na área Patrimônio Cultural, desde 2008, com ênfase nos seguintes temas: patrimônio

\footnotetext{
1. O presente artigo embasa-se nas reflexões que desenvolvi em minha dissertação de mestrado, denominada Meu bairro, minha cidade: as exposições inaugurais dos Centos Educacionais Unificados (CEUs) e as representações urbanas das periferias paulistanas, defendida em 2017 no Programa de Pós-Graduação Interunidades em Museologia da USP, sob orientação do Prof. Dr. Paulo César Garcez Marins.
}

arquitetônico; patrimônio industrial; moradia operária; memória urbana; representações sociais; curadoria e produção de exposições museológicas, com destaque para as memórias institucionais e processos curatoriais coletivos.

\section{Resumo}

O projeto Meu bairro, minha cidade: você também faz parte desta história, que resultou nas exposições inaugurais dos CEUs da primeira fase (2003-04), foi concebido no âmbito da Secretaria Municipal da Educação como um projeto de memória de bairros periféricos Desenvolvido no contexto das comemorações dos 450 anos da fundação da cidade de São Paulo (1554 2004) o projeto cumpria um duplo objetivo: evidenciar as conexões entre a história local e história mais ampla da cidade, visando a inclusão das memórias locais ao currículo escolar da rede municipal de ensino; e favorecer a apropriação positiva do novo espaço escolar pela população do seu entorno, então, reconhecida como agente construtor da cidade. Para enfatizar tais objetivos, optou-se pela inversão do eixo narrativo da história da cidade, do centro para a periferia, segundo a premissa que "a cidade começa no lugar onde você mora". Tal operação discursiva foi fundamentada em depoimentos dos moradores, que ora constituem o fio condutor do presente artigo, no sentido de abordar as conexões entre memória, identidade e território, bem como a definição de referenciais de memória, a partir de uma perspectiva distinta daquelas que orientam as políticas de patrimonialização.

Palavras-chave: Memória de bairro. CEUs. São Paulo (capital).

\section{Abstract}

The project $\mathrm{Meu}$ bairro, minha cidade: você também faz parte desta história, which resulted in the inaugura exhibits of the first phase CEUs (2003-04), was conceived within the Municipal Education Secretariat as a project of memory of peripheral neighborhoods. Developed in the context of the commemorations of the 450th anniversary of the founding of the city of São Paulo (1554-2004) the project fulfilled a twofold objective: to highlight the connections between local history and the wider history of the city, aiming at the inclusion of local memories in the school curriculum of the municipal school system, and favor the positive appropriation of the new school space by the population of its surroundings, then recognized as a building agent of the city. To emphasize these goals, we chose to invert the narrative axis of the city's history from the center to the periphery, according to the premise that "the city begins where you live". This discursive operation was based on the testimonies of the residents, which now constitute the guiding thread of this article, in order to address the connections between memory, identity and territory, as well as the definition of memory references, from a different perspective than those guiding the policies of patrimonialization.

Keywords: Neighborhood memory. CEUs. Sao Paulo (capital). 


\section{Relações entre memória, identidade e} território nos bairros-sede dos CEUs
Meus filhos sabem a história daqui. Tudo que veio aqui, tudo que estão fazendo aí hoje, essa iluminação pública, isso tudo tem cerca de três anos, que nós fomos lá, brigamos, (...). Para você ter uma ideia, água pra vim aqui pro bairro, foi do mesmo jeito, tivemos que enfrentar governador, deputados que se diziam donos da região, tudo isso... (...). As pessoas, às vezes, pensam: "não, tudo cai do céu..." (...) Por volta de 1994, apareceu aqui uma pessoa com o nome de Salim... Foi quem começou a criar isso aqui, vender lotes pras pessoas. (...) Aqui era só caminho, barraquinha, uma pobreza total. Quando foi em 96, nós recebemos uma reintegração de posse para os ex-proprietários, dos verdadeiros donos, no caso, a família Siqueira. (...) Quando nós chegamos aqui, tinha umas 80 famílias aqui (...) Nós éramos tratados de ladrão, nós éramos tratados como tudo que é ruim no mundo. (Antônio, CEU Paz, 2004)

0

ragmento em epígrafe faz parte do relato de um dos moradores do Jardim Paraná, extremo periférico da Vila Brasilândia, bairro localizado na Zona Norte da cidade de São Paulo onde foi construído o $19^{\circ}$ Centro Educacional Unificado (CEU Paz), inaugurado em abril de 2004. Esse relato integra o conjunto das transcrições das entrevistas realizadas no âmbito do projeto $\mathrm{Meu}$ bairro, minha cidade: você também faz parte desta história, concebido pela Secretaria Municipal da Educação e desenvolvido pela empresa Expomus - Exposições, Museus e Projetos Culturais, entre os anos de 2003 e 2004, como ação inaugural dos primeiros 21 Centros Educacionais Unificados.

Estruturado com o objetivo de recolher e refletir sobre as memórias de bairro, o projeto deu origem às exposições inaugurais dos CEUs, e teve seu início marcado pela realização de uma pesquisa de campo que envolveu registros de história oral e coleta de documentos e de material iconográfico junto aos moradores e entidades locais. Realizado no contexto das comemorações dos 450 anos de São Paulo (1554-2004) e tendo 
como fio condutor a problematização da construção da cidade, os pesquisadores buscavam estabelecer as conexões entre as histórias locais e a historiografia oficial, bem como compreender as dinâmicas de cada território e o modo como os bairros periféricos dialogam com o centro.

O presente artigo tem por objetivo abordar o conteúdo desses registros de história oral, buscando evidenciar as relações entre memória, identidade e território presentes nas narrativas dos moradores entrevistados. Será também analisada a conversão de tais conteúdos em discurso expositivo, organizados segundo a premissa: "a cidade começa no lugar onde você mora", como marca da inversão do eixo de análise do centro para a periferia.

Considerando que as exposições cumpriam o objetivo de ação inaugural dos CEUs, também serão observadas as circunstâncias da implantação desses novos equipamentos, então integrados a um plano municipal de intervenção no território da cidade, que envolvia tanto ações nas áreas centrais quanto nas periferias. Por fim, será destacada a dimensão pedagógica do projeto, segundo a proposta de inclusão da memórias locais ao currículo escolar, como estratégia de produção de conhecimento sobre a cidade e na perspectiva da escola como um centro de memórias do território.

\section{Narrativas de vida como um valor a ser transmitido aos mais jovens}

Os registros de história oral, obtidos por meio de entrevistas com os moradores, entre 2003 e 2004, durante o desenvolvimento da pesquisa de campo de Meu bairro, minha cidade, foram transcritos e organizados em 21 cadernos, sendo um para cada CEU, totalizando 1.105 páginas (EXPOMUS, 2004b). Nesse processo, somando os registros das narrativas dos moradores à documentação e às imagens coletadas em campo, o projeto das exposições inaugurais foi capaz de reunir um importante acervo sobre a constituição dos bairros pesquisados no âmbito do projeto.

A análise das transcrições das entrevistas com os moradores nos dá conta de narrativas sobre a apropriação do espaço e a sua transformação em cidade. Esses relatos, que são memórias do vivido, mesclam as esferas público e privado. $\mathrm{Na}$ fala dos mais velhos, os discursos são marcados pelo "pioneirismo" da apropriação do espaço, por meio de expressões como "isso aqui era tudo mato", seguidas por "hoje aqui é uma cidade". É evidente, nessas falas, o orgulho desses moradores com o desenvolvimento do lugar que eles ajudaram a construir.

Tais narrativas evidenciam o processo de transformação urbana como o resultado de lutas sucessivas, desde a posse da terra, as ações por melhorias de infraestrutura e a conquista de equi- 
pamentos públicos, indicativos da transformação daquele espaço em cidade: a primeira linha de ônibus, a construção de uma ponte, as obras de contenção de enchentes. Entre esses marcadores de urbanidade, ainda são mencionadas farmácias, agências bancárias, supermercados, lojas de rede, bares, campos de futebol, igrejas, lugares de festas e as associações de bairro, tudo aquilo que é compreendido como o resultado de lutas coletivas e cotidianas, que se configuram como referenciais materiais das memórias locais.

Todavia, é importante salientar que tais referenciais compõem um rol muito distinto daqueles tradicionalmente legitimados suportes de memórias ou patrimônios dignos de proteção governamental. Os conceitos de patrimonialização e tombamento, que se baseiam tradicionalmente nas noções de ancianidade e de monumentalidade, não se aplicam a esses indicadores locais, visto que são recentes, "banais" e estão em permanente transformação. Para os moradores, porém, a lógica da atribuição de valor cultural está na relação dos lugares com o trabalho ou em função da relevância social de um determinado bem associado à melhoria das condições materiais de vida ou que foi e é capaz de dar suporte às relações sociais.

As próprias relações sociais, de parentesco e amizade, nesse caso, são compreendidas como referenciais intangíveis de memória, pois dão sentido ao cotidiano, como as bases da sobrevi- vência na periferia e por meio das quais é constituído o sentimento de pertencimento a um grupo que assim se define territorialmente. Segundo Magnani (2004, p. 34), trata-se de reconhecer o morador da periferia no contexto de suas práticas sociais e a existências das redes de sociabilidade enquanto "formas de autopreservação, de associação - sem as quais a vida social, nas suas múltiplas dimensões, há muito estaria impossibilitada, no cenário da megalópole".

O relato de João Vitalino, morador do Jardim Três Corações/Grajaú, na Zona Sul paulistana, onde foi construído o CEU Três Lagos (2003), evidencia a importância das redes de sociabilidade das quais trata Magnani. Em sua narrativa, ele salienta a existência de uma "colônia de parentes" que Ihe deu suporte quando chegou em São Paulo, bem como as amizades e a configuração da "comunidade" que luta para a solução de problemas comuns, a partir da qual ele se constituiu como liderança local:

No Nordeste, todo mundo vem migrar para São Paulo. A gente veio nesse embalo. Quando vem um, vem todo mundo. E ficamos por aqui, e aqui estamos(...) Minha história... (...). Vim de caminhão pau de arara, quando a Rio-Bahia ainda era de terra. (...) Vim parar em [Cidade] Ademar porque já tinha parente na Zona Sul. E onde tem parente, você sabe, a gente forma uma colônia de parente, é onde tem apoio do pessoa parente, porque estranho não dá coração pra gente. 
(...) Daí vim para esse Jardim [Três Corações] e comprei um barzinho. Agora isso faz 32 anos. (...) A gente tinha uma casa e nada mais. O resto era tudo roça de mandioca e milho. (...) Isso aqui não tinha asfalto nenhum. (...) Era só mato, mineração de areia, trabalhador da mineração, a represa, seis ônibus. Mais nada.

Claro que quis vim pra cá; aqui é que era o lugar, não tinha comércio, não tinha nada, era aqui que eu podia começar, que eu podia ganhar dinheiro, como ganhei. Eu sabia que isso aqui ia crescer, como cresceu. Tiveram alguns problemas na vida, mas não adianta dizer que não porque eu ganhei dinheiro sim, isso eu ganhei.

Se eu gosto daqui? Demais mesmo. Adoro. Se falar que eu tenho que mudar daqui eu não vou, não mudo mesmo. Aqui eu formei minha família, aqui é onde o pessoal estudou, aqui é onde eu tenho conhecimento, não tenho problema com nada.

(...) a gente vive muito bem aqui com amizade da escola, da gente do posto de saúde. Eu tenho em torno de mim umas 18 entidades do bairro, entre igreja, campo de futebol, entidade mesmo. Todo mundo traz tudo na minha casa. Que que eu quero mais? Dinheiro não é felicidade da pessoas. O que eu ganho a gente vai vivendo. Mas o bom mesmo é ter assim, uma tranquilidade.

(...) Nós estamos aqui com 740 mil habitantes, contando com Parelheiros, Cocaia e Varginha, nossa região. Isso dá um monte de gente. A gente é comunidade, tem que estar aqui, tem que estar vendo, escutando.
Eu faço parte do orçamento participativo. Estou envolvidíssimo com a subprefeitura, mostrando todos os problemas. Qualquer problema aqui eu vou apontar. Seja ponto de ônibus irregular, lâmpada quebrada, córrego sujo. E às vezes eles dizem que não dá e eu falo: "dá sim, vamos fazer já". E eles fazem. Porque eu estou com a comunidade todos os dias. Quando eu não estou, alguém vem me chamar. (João Vitalino, 2003)

Além de destacar o papel das redes de sociabilidade como elemento de sustentação pessoal e de organização do território, o relato de João Vitalino também sublinha um dado comum às transcrições analisadas, sobretudo entre os moradores mais velhos e dos bairros mais antigos, que é a experiência da transição entre o rural e o urbano ("era tudo roça de mandioca e milho"). No caso desses bairros já consolidados à época da construção dos CEUs, o processo de urbanização ocorreu a partir do loteamento de antigas chácaras, ou no entorno de conjuntos habitacionais e vilas operárias situadas no limite da mancha urbanizada. O desenvolvimento urbano, em vista disso, aconteceu de forma institucionalizada, embora precária.

Entretanto, nos bairros mais novos, que ainda estavam em processo de formação quando os CEUs foram implantados, as narrativas ainda tratavam da luta pela posse da terra, a conquista da moradia e de infraestrutura básica. Assim era o caso do Jardim Paraná (CEU Paz, 2004), 
uma ocupação de área de proteção ambiental na Serra da Cantareira, em 1993, por moradores desalojados de favelas localizadas na Vila Brasilândia. Esse caso elucida a recorrente expulsão de camadas da população para áreas cada vez mais extremas da cidade. As sucessivas exclusões, dificultam a organização dos moradores e a formação de liderança, bem como a criação de vínculos estáveis com o território, tendo em vista que os mesmos vivem um constante provisório.

Nos bairros mais antigos, a organização dos moradores e a constituição de lideranças configurou-se nas décadas de 1970-1980, no âmbito de movimentos sociais de base, com o apoio de igrejas, sindicatos e partidos políticos. Tais grupos foram capazes de conquistar significativas melhorias para esses bairros, atualmente bem infraestruturados. Nesses casos, são comuns os relatos de um passado de lutas, mas também de prosperidade, sendo que parte desses narradores são lideranças locais reconhecidas, tornando evidentes as construções identitárias vinculadas ao território e o orgulho que demonstram ao descrever o lugar que ajudaram a construir.

Um exemplo de tais construções identitárias é o relato de Antônio Ermírio, morador do Jardim Três Corações/Grajaú, Zona Sul, onde foi construído o CEU Três Lagos (2003), que revela um domínio tanto do território quanto de um discurso de poder, narrando-se como benfeitor do bairro, em articulação com o poder público.
Quando eu cheguei aqui, tinha uns 10 moradores. Sou proprietário no bairro desde 1962 e morador desde 1966. Eu vim de Santo Amaro direto pra cá. Me arranchei aqui. É amor por Três Corações. A gente se arranjou de uma maneira e hoje vê esta cidade.

Nós fizemos uma comissão pra conseguir uma rua de asfalto, uma escola e um telefone, na época do Setúbal. Aí nós conseguimos fazer o serviço social em benefício da população $e$ nós ajudamos na medida do possível. Trabalho social é cobrar luz, cobrar escola, cobrar melhoramentos no bairro, para a Prefeitura e o Estado. É distribuir leite, distribuir cestas.

A relíquia que eu mais tenho é agradar o povo. Nem tudo eu posso agradar (...). Aqui é meu registro. Só saio daqui para o cemitério. (...) Porque eu vi isso aqui pequenininho, agora é uma cidade. $\mathrm{E}$ agora eu quero trazer mais melhoramentos, eu quero mais conforto. O povo é muito simples, mas não é uma área totalmente carente. Tem algumas favelas, é verdade, mas não é a maioria. E é uma relíquia o quanto eu sou conhecido aqui, todo mundo me conhece. Na medida do possível, enquanto vida eu tiver, eu vou lutar por isso. (Antônio Ermírio, 2003)

Ao contar sobre a formação da comissão de moradores para conseguir melhorias para o bairro,

Antônio Ermírio apresenta-se como membro de um grupo de moradores ("nós fizemos uma comissão"). Em seguida, destaca-se do grupo de moradores ("a população", "o povo") e expressa o seu ingresso em um grupo de líderes locais ("nós conseguimos fazer o serviço social em benefício da população"). Ao final, ele assume o discurso 
do benfeitor local ("a relíquia que eu mais tenho é agradar o povo"; "e agora eu quero trazer mais melhoramentos, eu quero mais conforto").

Tal construção é representativa de três tempos distintos: o passado e a configuração do grupo (comunidade); um tempo intermediário onde ele se destacou como liderança, juntamente com outros membros do grupo; e o tempo presente, no qual a sua condição de liderança encontra-se consolidada. Investido dessa posição de líder e apresentando-se como benfeitor local, Antônio Ermírio inscreve-se no espaço percebido como de seu domínio, com a expressão "aqui é o meu registro”. Conforme observam Font \& Rufí (2006, p. 38), "o lugar proporciona o meio fundamental pelo qual damos sentido ao mundo e por meio do qual atuamos", assim, "quando 'vivemos' os lugares, criamos identidades. Falar de lugar, portanto, é falar de identidade".

Desse modo, podemos identificar, como elemento comum às narrativas tomadas como exemplo, a reinvindicação de um espaço social e político de atuação que está vinculado à construção do território onde esses agentes sociais estão inscritos, portanto, constituintes de representações sociais, individuais e coletivas. Entretanto, ao serem adotadas como base do discurso expositivo de Meu bairro, minha cidade, assumem um caráter comunicativo dos valores compartilhados pelo grupo.
Para elaboração do discurso expositivo, a solidariedade, a participação, a responsabilidade ambiental, o elo afetivo com o lugar e a inclusão do bairro como parte da cidade foram definidos como os valores a serem evidenciados na composição dos painéis. Desse modo, o recorte dos relatos dos entrevistados pela equipe responsável por conceber a exposição teve como critério de seleção a identificação desses mesmos valores. O propósito era que os mais velhos, sobretudos as lideranças, fossem percebidos pelos mais jovens como exemplos a serem seguidos. Nessa perspectiva, os problemas da atualidade do bairro foram postos como "desafios a serem vencidos" pelo grupo, que ora inseria os mais jovens no contínuo exercício de lutas e conquistas.

Do mesmo modo, enquanto ação inaugural dos CEUs e por meio de uma complexa operação simbólica, Meu bairro, minha cidade tanto inseria os moradores no espaço do CEU quanto cravava o novo equipamento na paisagem, impondo-o como marco cívico, sobretudo, ao definir a escola como um centro das memórias locais. Por fim em escala ampliada, inseria o bairro no espaço mais amplo da cidade.

\section{Meu bairro, minha cidade como ação inaugural dos CEUs}

Constituído a partir de um diálogo entre profissionais das áreas da educação, da museologia e da antropologia, reunidos pela Expomus, o projeto 
Meu bairro, minha cidade visava abordar as relações entre a memória, a identidade e a constituição dos territórios em que se situavam os CEUs. Para isso, era preciso compreender tanto a inserção do novo equipamento no cotidiano dos bairros quanto criar condições para que o mesmo fosse positivamente apropriado pela população local. Os CEUs deviam também, ser incluídos no rol dos referenciais locais, bem como ser reconhecidos como um esforço daquela gestão em dotar a periferia de equipamentos públicos de qualidade.

Torna-se indispensável, portanto, relacionar o projeto das exposições inaugurais ao próprio projeto de implantação dos CEUs, sobretudo, enquanto peça integrante de um plano estratégico de desenvolvimento urbano e de intervenção no território da cidade. Tal plano envolvia ações simultâneas nas áreas centrais e nos bairros periféricos, lastreadas pelo reconhecimento crítico da cidade como um território fragmentado, marcado pela segregação socioespacial e definido pela oposição semântica centro-periferia.

No entendimento da gestão municipal de Marta Suplicy (2001-2004), a periferia foi definida como um território de exclusão, constituído na ausência do poder público e em função do descaso das gestões anteriores. A implantação dos CEUs deve, assim, ser compreendida no contexto de um discurso político apoiado em ações afirmativas de inclusão social e cidadania e como um ato de ordenamento urbano. Nesse sentido, a opção de erguerem-se os CEUs com uma arquitetura monumental, centralizadora e de grande impacto na paisagem local, tanto foi capaz de marcar a presença do poder público municipal nas periferias, como um ponto de inflexão das políticas urbanas, representando a inserção simbólica da periferia no território político da metrópole.

Formalizada por meio de uma Operação Urbana (SME P3.1-83v), a implantação dos CEUs foi constituída como uma ação coordenada pela Secretaria Municipal da Educação, em colaboração com as secretarias da Cultura e do Esporte e Lazer, que envolveu todos os setores sociais do governo. Assim, para além das suas funções como equipamentos multifuncionais de educação, cultura, esporte e lazer, os CEUs cumpriam o objetivo de atuar como polos de convergência das políticas sociais do governo e vetores de desenvolvimento dos territórios onde estavam sendo inseridos. No âmbito da cultura, os CEUs deveriam atuar como atrator das manifestações locais, ao mesmo tempo em que eram inseridos no circuito cultural da cidade.

A despeito das pretensões simbólicas do projeto arquitetônico dos CEUs, o seu caráter monumental, de grande impacto na paisagem local, também causou estranhamento e desconfiança por parte da população do seu entorno. Para que os objetivos da política de intervenção urbana pudessem ser atingidos, era necessário que o novo 
equipamento fosse apropriado favoravelmente. Por outra via, a efetivação dos CEUs como um centro de desenvolvimento local estava condicionada ao entendimento das dinâmicas dos territórios onde esses equipamentos estavam inseridos e sobre os quais o poder público pretendia atuar. Tratava-se, portanto, de uma dupla apropriação. Foi nesse contexto que se deu a concepção de uma ação inaugural museológica fundada em um projeto de memória de bairro, com o objetivo de abarcar tais dinâmicas internas ao território e, no cenário das comemorações dos 450 anos da cidade, compreender como os bairros dialogam com o centro. A expectativa da gestão municipal era que a adesão dos moradores ao projeto, no âmbito da pesquisa de campo, conforme abordado anteriormente, pudessem favorecer tal apropriação positiva.

A opção pela divulgação da pesquisa de campo por meio das exposições fundava-se na ambição de que os moradores se sentissem retratados e homenageados pelo poder público. Por outra via, ambicionava-se que os mesmos fossem capazes de perceber os vínculos concretos e simbólicos entre a história da cidade e as dinâmicas da constituição dos bairros-sede dos CEUs, então, reconhecidos como agentes construtores da cidade que comemorava 450 anos de fundação.

No âmbito do projeto político-pedagógico (SME ${ }^{*}$ P5.1/60A), tal iniciativa ganhava uma dimensão mais abrangente, pois se almejava que os con- teúdos produzidos para a exposição fossem absorvidos e desenvolvidos em ações na sala de aula. Desse modo, o tema das memórias locais seria integrado ao currículo da rede municipal de ensino, convertendo cada aluno em pesquisador do seu território e como produtor de conhecimento sobre a cidade. As próprias exposições inaugurais deveriam, nesse sentido, serem substituídas por outras concebidas nos próprios CEUs.

\section{A inversão do eixo narrativo: "a cidade começa no lugar onde você mora"}

O texto apresentado no painel de abertura de cada uma das exposições dos CEUs corresponde a uma operação de inversão do eixo narrativo sobre a construção da cidade. Como pode ser observado na transcrição a seguir, após apresentar a versão oficial da cidade, fundada em 1554 por padres jesuítas, e tendo como marco o Pátio do Colégio, no centro, declara-se: "a cidade começa no lugar onde você mora".

Em 25 de janeiro, a cidade de São Paulo vai festeja seu aniversário. São 450 anos de história, desde que os padres Manuel da Nóbrega e José de Anchieta construíram o pequeno colégio dos jesuítas no planalto de Piratininga, onde a cidade começou. Hoje São Paulo tem mais de 10 milhões de habitantes. A cidade é tão grande que, para poder administrá-la, foi preciso criar 31 subprefeituras nas diferentes regiões da cidade. 
Este é o mapa de São Paulo. Para você, cidadão paulistano, a cidade começa onde você mora. Este é o seu bairro. Você também faz parte dessa história. (EXPOMUS, 2004b, p. 1)

Por meio dessa operação simbólica, a periferia foi posta em evidência e integrada ao território da cidade. A partir desse ponto, o discurso expositivo, constituído pela articulação passado-presente-futuro, prosseguia com a narrativa da história da formação do bairro como o resultado das lutas coletivas na conquista do espaço e por meIhores condições de vida. Nessa mesma lógica, os problemas urbanos foram apresentados como "desafios a serem vencidos". A mesma narrativa também evidenciava as lideranças locais, na qualidade de "gente que faz a diferença" e, na sequência, convidava os mais jovens a seguirem nessas conquistas.

A construção dessa nova imagem para os bairros e para a própria cidade, pela chave do reconhecimento de sua diversidade territorial, implicava o reconhecimento da contribuição de múltiplos sujeitos sociais envolvidos na construção da capital, a partir da concentração de conhecimentos e culturas trazidas por migrantes e imigrantes de todas as partes do Brasil e do mundo. Nesse sentido, a construção desse novo olhar sobre a cidade, encontrava nos CEUs a materialização dos discursos de inclusão social e, nas suas exposições inaugurais, a expressão das políticas afirmativas e identitárias vinculadas ao território.
Essa operação de inversão do eixo interpretativo da cidade, do centro para a periferia, era complementada e aprofundada pela proposta de inclusão do tema das memórias locais ao currículo escolar da rede municipal de ensino. Tal inclusão, compreendida como a dimensão pedagógica das exposições inaugurais, definia a escola como espaço privilegiado para a produção do conhecimento sobre a cidade, a partir das dinâmicas do território.

\section{A dimensão pedagógica: escola como centro} de memórias locais

A inclusão do tema das memórias locais ao currículo escolar, convertendo cada aluno em um pesquisador em seu território e a partir de sua própria rede de sociabilidade, para além de ampliar o alcance da pesquisa de campo, propunha uma inversão de eixo, também, na produção do conhecimento sobre a cidade. A dimensão pedagógica de Meu bairro, minha cidade, concebida como um elemento de reflexão e aprofundamento das exposições, dava-se por meio de material didático próprio, composto por dois cadernos distintos, destinados aos alunos e professores.

Nesse sentido, o objetivo das atividades propostas era possibilitar que os alunos reproduzissem a metodologia empregada na pesquisa de campo que deu origem às exposições. De acordo com o relatório produzido pela Expomus, o Caderno de Atividades permitia aos alunos tanto a apro- 
priação do processo de criação das exposições quanto o desenvolvimento de elementos relativos à identidade e pertencimento ao lugar:

Ao tomarem contato com os conteúdos que - Caderno de Atividades introduz e serem convidados a participar como personagens dessa história, a criança leitora ou o jovem leitor passam a ser não somente coautores dos pequenos livros que estão compondo, como também a se reconhecerem como agente de sua própria história. Utilizando-se da escrita, do desenho e da colagem para expressar a percepção de sua própria realidade, bem como sua visão de mundo e sua busca por caminhos de futuro, estas crianças e jovens poderão expressar percepções, sensações e emoções, compartilhando valores, ideias, projetos sonhos. (EXPOMUS, 2004a, p. 4)

Considerando os objetivos expostos acima, o material pedagógico possibilitava a produção de narrativas apoiadas em distintos suportes e meios, de acordo com a faixa etária, a aptidão e preferência de cada aluno. Entretanto, em função de limitações orçamentárias, foi produzido um único Caderno de Atividades para dar conta de um arco etário, correspondente ao ensino fundamental, que, no plano do ideal, vai de 6 a 14 anos. A tentativa de superação imposta por um material produzido nessas circunstâncias, resultou na produção do Caderno do Professor, contendo sugestões de atividades a serem desenvolvidas para as diferentes faixas etárias e na perspectiva de diferentes disciplinas escolares.
Tendo em vista a complexidade dos objetivos simbólicos do projeto, conforme exposto anteriormente, o efetivo desenvolvimento da dimensão pedagógica de $\mathrm{Meu}$ bairro, minha cidade dependia, mais do que do material didático, de formação específica e continuada de professores e demais profissionais envolvidos no processo de ensino-aprendizagem. Entretanto, isso não ocorreu em nenhum momento do processo. Embora a concepção e desenvolvimento do projeto tenha sido acompanhada por especialistas da área da educação, os professores da rede, mesmo que de forma representativa, não foram chamados a participar.

Em função disso, a dimensão pedagógica do projeto, apesar de compreendida como a sua principal condicionante e, acima de tudo, como o aspecto mais emblemático de Meu bairro, minha cidade, acabou por ser eclipsada. A partir de 2005, concluída a gestão Suplicy, o projeto foi descontinuado.

Todavia, a perspectiva da inclusão das memórias locais ao currículo escolar está vinculada, no plano da educação, aos princípios da educação integral, que nortearam a concepção dos CEUs e, por consequência, o projeto das suas exposições inaugurais. Em vista disso, a experiência de $\mathrm{Meu}$ bairro, minha cidade, apesar de seu ofuscamento a partir de 2005, não se perdeu de todo. Desde 2017 , está em curso um novo projeto da Secretaria Municipal da Educação, desenvolvido no âm- 
bito da Coordenadoria dos CEUs e da Educação Integral (COCEU), denominado CEU, memórias e ação.

O novo projeto, que envolve as atuais 46 unidades dos $\mathrm{CEUs}^{2}$, está fundamentado na formação de professores e demais profissionais envolvidos no processo de ensino-aprendizagem. Tal projeto adota Meu bairro, minha cidade como uma de suas referências, juntamente com outros projetos desenvolvidos pontualmente nas escolas da rede, igualmente compreendidos como iniciativas exemplares. Contudo, ao contrário do caráter centralizador do projeto das exposições inaugurais, o atual estimula o desenvolvimento de atividades definidas em cada unidade dos CEUs, como o resultado de negociações internas aos territórios.

O texto elaborado para esse novo projeto (SME/ COCEU, 2017, p. 1) reforça o caráter dos CEUs como "espaços integradores e integrados" e define seus objetivos como o de "construir, resgatar e organizar as memórias dos equipamentos e do entorno no qual estão inseridos". Para tanto, esclarece, "será necessária a articulação de todos os envolvidos, promovendo assim a integração dos sujeitos de direitos e deveres que fazem parte dos CEUs, sendo como funcionários, moradores, estudantes, frequentadores, usuários dos espaços". Nesse quadro, os CEUs são compreendidos como "espaços privilegiados de reflexão sobre os arredores da cidade e dos pró- prios locais onde estão inseridos" e, em seguida, define-os como "centros de referências de memória dos territórios".

Mais adiante, o mesmo documento (Op. cit. p. 2) reforça que é responsabilidade de todos os envolvidos o "comprometimento com as histórias que abriga", bem como a "necessidade de fazer com que toda a população usuária do equipamento CEU, seja autora e protagonista". Assim, é objetivo do projeto fomentar "elos de sentido e significados dos acervos materiais e imateriais locais", com vistas a contribuir para a "formação da história da população paulistana".

Desse modo, o atual projeto representa o almejado aprofundamento de Meu bairro, minha cidade, efetivando a ampliação do seu alcance, na medida em que cumpre aquilo que foi proposto por sua dimensão pedagógica, contudo, sem o seu caráter centralizador.

\section{Considerações finais}

No âmbito das políticas patrimoniais, o projeto Meu bairro, minha cidade representa uma das mais importantes inciativas culturais acionadas pela esfera pública municipal, especialmente por seu caráter inédito de registro de memórias de bairros periféricos. Ao longo do seu percurso, entre 2003 e 2004, o projeto reuniu um rico acervo de registro de história oral, de documentos textuais e de material iconográfico sobre os bairros 
pesquisados. E, embora suas ambiguidades e fragilidades, as exposições dele resultantes foram capazes de produzir uma narrativa que rompia o discurso hegemônico da cidade que ressaltava o protagonismo das suas elites, promovendo a inclusão de novos sujeitos no rol dos seus construtores e, principalmente, reconhecendo-os como autores de discursos sobre ela.

A proposta da inversão do eixo de análise da cidade, do centro para a periferia, bem como a definição de referenciais de memória, a partir de uma chave distinta daquelas adotadas pelas políticas de patrimônio, são igualmente emblemáticas desse projeto museológico. Tais rompimentos e inversões interpretativas constituem elementos importantes para as reflexões sobre a cidade, compreendida por Ulpiano Toledo Bezerra de Meneses (2003, p. 258), como "um objeto de conhecimento mais amplo e complexo do que qualquer acervo ou documento que possa referenciá-lo".

O projeto de memória de bairro, comunicado por meio das exposições inaugurais dos CEUs, ainda inova ao definir o espaço escolar como lugar de uma ação museológica, ampliando sobremaneira as possibilidades de interação entre a experiência museal e a escola, compreendidas como duas dimensões formadoras comprometidas com a produção do conhecimento e a circulação de valores. A ação museológica e a Educação, nesse caso, foram compreendidas como constituintes de uma política pública de memória urbana que, a partir de um novo olhar sobre a cidade, apontava para uma nova forma de atuar no território, reconhecendo e promovendo as transformações sociais.

\section{Referências Bibliográficas}

ASSMANN, Aleida. Espaços de recordação: formas de transformações da memória cultural. Campinas, SP: Editora da Unicamp, 2011.

BAUMAN, Zygmund. Identidade: entrevista a Benedetto Vuchi. Rio de Janeiro: ZAHAR, 2005.

CARDOSO, Ruth Correia Leite. Movimentos sociais na América Latina. São Paulo,1987.

CURY, Marília Xavier. Análise de exposições antropológicas: subsídios para uma crítica. XIII Encontro Nacional de Pesquisa em Ciência da Informação: Rio de Janeiro, 2012.

\section{Comunicação Museológica - Uma perspectiva teórica e metodológica de recep- ção. Tese de Doutoramento. São Paulo: USP,} $2005 a$.

ESTANISLAU, Lídia Avelar. O papel do Estado democrático na proteção dos lugares de memórias. In: A construção da cidade. Brasília: DPH/ DF, pp.61-81, 1998. 
FONT, Joan Nogué; RULÍ, Joan Vicente. Geopolítica, identidade e globalização. São Paulo: Annablume, 2006.

HADLER, Maria Silvia Duarte; BERNARDES, Maria Elena. Memória e escolar: olhares sensíveis para um patrimônio cultural. São Paulo: Ver. Horizontes, v. 35, n. 1, p. 59-70, 2017.

HALBWACHS, Maurice. A memória coletiva. São Paulo: Vértice Editora Revista dos Tribunais, 1990.

HALL, Stuart. A Identidade Cultural na pós-modernidade. Rio de Janeiro: Lamparina, 2015.

HUYSSEN, Andreas. Seduzidos pela memória. Rio de Janeiro: Aeroplano, 2004.

KHELL, L.A.B. Breve História das Favelas. São Paulo: Claridade, 2010.

MAGNANI, José Guilherme Cantor. De perto e de dentro: um novo olhar sobre a cidade. Revista FGV Executivo, v.12, n.2, jul./dez. São Paulo: FGV, 2013, pp.38-41.

. (Org.) Expedição São Paulo 450 anos: uma viagem por dentro da metrópole. São Paulo. Secretaria Municipal da Cultura. Instituto Florestan Fernandes, 2004, pp.33-35.
MENESES, Ulpiano Bezerra Toledo de. O museu de cidade e a consciência da cidade. Conferência proferida no encerramento do Seminário "Museus \& Cidades": São Paulo, 2003.

NORA, Pierre. Memória: da liberdade à tirania. Revista Musas no 4, p. 6-10, 2009.

PEREZ, Maria Aparecida. A inclusão social através da educação, formação e cultura: um estudo do programa dos CEUs em São Paulo. Tese de Doutorado: Universidade de Siegen (Alemanha), 2010.

PFEIFFER, Claudia Castellanos. Cidade e sujeito escolarizado. In: ORLANDI, Eni de Lourdes Puccinelli. Cidade atravessada: os sentidos públicos do espaço urbano. Campinas, SP: Pontes, 2001.

RODRIGUES, Marly. Patrimônio, ideia que nem sempre é prática. In: A construção da cidade. Brasília: DPH/DF, pp.82-84, 1998.

SANTOS, Milton. A urbanização desigual: a especificidade do fenômeno Urbano em países subdesenvolvidos. São Paulo: Edusp, 2012.

Pensando o espaço do homem. $5^{\mathrm{a}}$. Ed, São Paulo: Editora USP, 2007. 


\section{Documentos}

EXPOMUS. Meu bairro, minha cidade: você também faz parte desta história. Relatório final de prestação de contas. São Paulo, 2004a.

Meu bairro, minha cidade: você também faz parte desta história. Cadernos com as transcrições das entrevistas de campo (21 volumes). São Paulo, 2004b.

Meu bairro, minha cidade: você também faz parte desta história (Conjunto de publicações com: cadernos das exposições (21 volumes); caderno de atividades; caderno do professor; mapas e materiais de divulgação. São Paulo, 2004c.
PREFEITURA MUNICIPAL DE SÃO PAULO, SECRETARIA MUNICIPAL DA EDUCAÇÃO. Documentos: *H1.1/31 (Educação, CEU e Cidade); *P5.1/60 A (Projeto político pedagógico dos CEUs); *P2.1/64 (Plano de Metas para a Educação/2001-2004); *P3.1/83 1 ${ }^{\text {a }}$ (CEU a escola que queremos); *P3.1/83v (Operação urbana CEU); *P3.1/83z (Educação com qualidade social: a experiência dos CEUs em São Paulo); *P3.1/108d (A construção de uma trajetória para a escola pública municipal); *P3.1/108f (Implementação da rede de proteção social). São Paulo, 2002.

Projeto CEU, Memórias e Ação: a importância social dos equipamentos CEUs. COCEU/SME, São Paulo, 2017. 